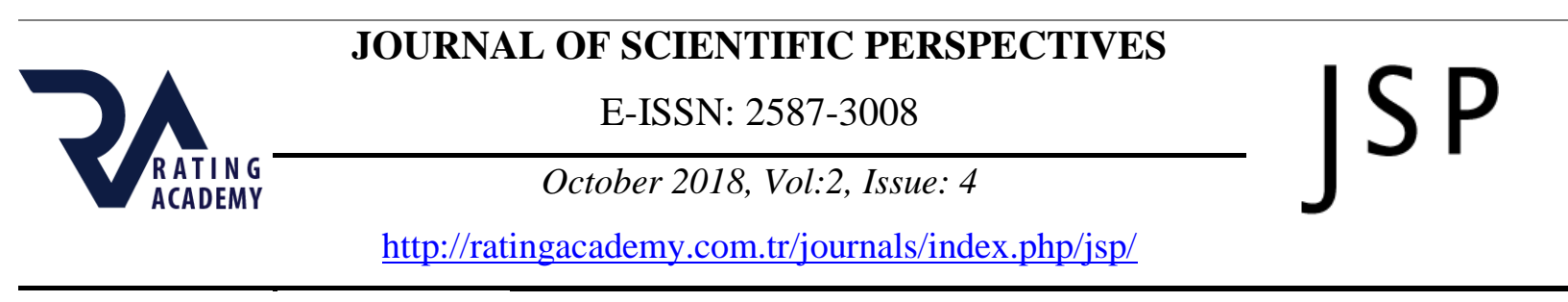

\title{
WIRELESS SYSTEM FOR TEMPERATURE MONITORING IN A VOLCANIC AREA BY USING ZIGBEE TECHNOLOGY: INITIAL CONCEPTS AND PROJECT
}

\author{
Ramiro Sebastian VARGAS \\ PhD student Doctoral School on Material Sciences and Technologies, \\ Obuda University, HUNGARY \\ E-mail:vargas.ramiro@phd.uni-obuda.hu
}

Lourdes RUIZ

PhD Student Doctoral School on Safety and Security Sciences,

Obuda University, HUNGARY

E-mail:lourdes.ruiz@bgk.uni-obuda.hu

Maria Cristina Navas LEMA

Universidad de las Fuerzas Armadas ESPE, ECUADOR

E-mail:mcnavas@espe.edu.ec

Mustahsan SHUAIB

Miskolcs University, HUNGARY

E-mail: mustahsan.abbasi@gmail.com

\begin{tabular}{l|l}
\hline \multicolumn{1}{c|}{ ARTICLE INFO } & \multicolumn{1}{c}{ ABSTRACT } \\
\hline $\begin{array}{l}\text { Article History: } \\
\text { Received: } 9 \text { September } 2018 \\
\text { Accepted: 8 October } 2018\end{array}$ & $\begin{array}{l}\text { Volcanic areas in Ecuador are certainly a topic that concerns the population. } \\
\text { National and international institutes have carried out constant monitoring to be } \\
\text { aware of the volcanic activity. Thus, stationary monitoring equipment was } \\
\text { installed along the volcanic belt. However, this control stations cannot really }\end{array}$ \\
$\begin{array}{ll}\text { Keywords: Temperature } \\
\text { monitoring, mobile wireless } \\
\text { technology, ZigBee. }\end{array}$ & $\begin{array}{l}\text { mobile equipment which constantly measures the temperature. The temperature is } \\
\text { sent to the control station using ZigBee technology and reliable sensors. The half- } \\
\text { duplex communication allows the user to manipulate the mobile system and } \\
\text { observe the measured temperature in the same controller. }\end{array}$ \\
\hline $\begin{array}{l}\text { DOI: } \\
\text { 10.26900/jsp.2018445372 }\end{array}$ & \\
\hline
\end{tabular}

\section{INTRODUCTION}

Ecuador is located in the Ring of Fire of the Pacific, which is comprised by a string of volcanoes and sites of seismic activity. Approximately $90 \%$ of the earthquakes take place in this area. Moreover, $75 \%$ of all the active volcanoes on Earth are situated in this ring. Ecuador harbors a large number of volcanoes (National Geographic, 2018). Volcanoes' classification comprised of three groups based on their eruption history. However, for the sake of practical application a fourth type is added for describing the volcanoes that have been in eruption over the last few decades.

1. Extinct or Inactive: the last eruption was more than 10000 years ago. 
2. Potentially active: the last eruption was less than 10000 years ago.

3. Active: the last eruption was more than 500 years ago.

4. In eruption: had eruptive activity in 2011 .

According to the Institute of Geophysics of Ecuador, it possesses 84 volcanoes, 27 are potentially active in the continental area and the Galapagos Islands (Instituto Geofisico Ecuador, 2018). Figure 1 shows the state of the volcanoes in the Ecuadorian continental area.

Figure 1. Volcano Activity classification in Ecuador continental area.

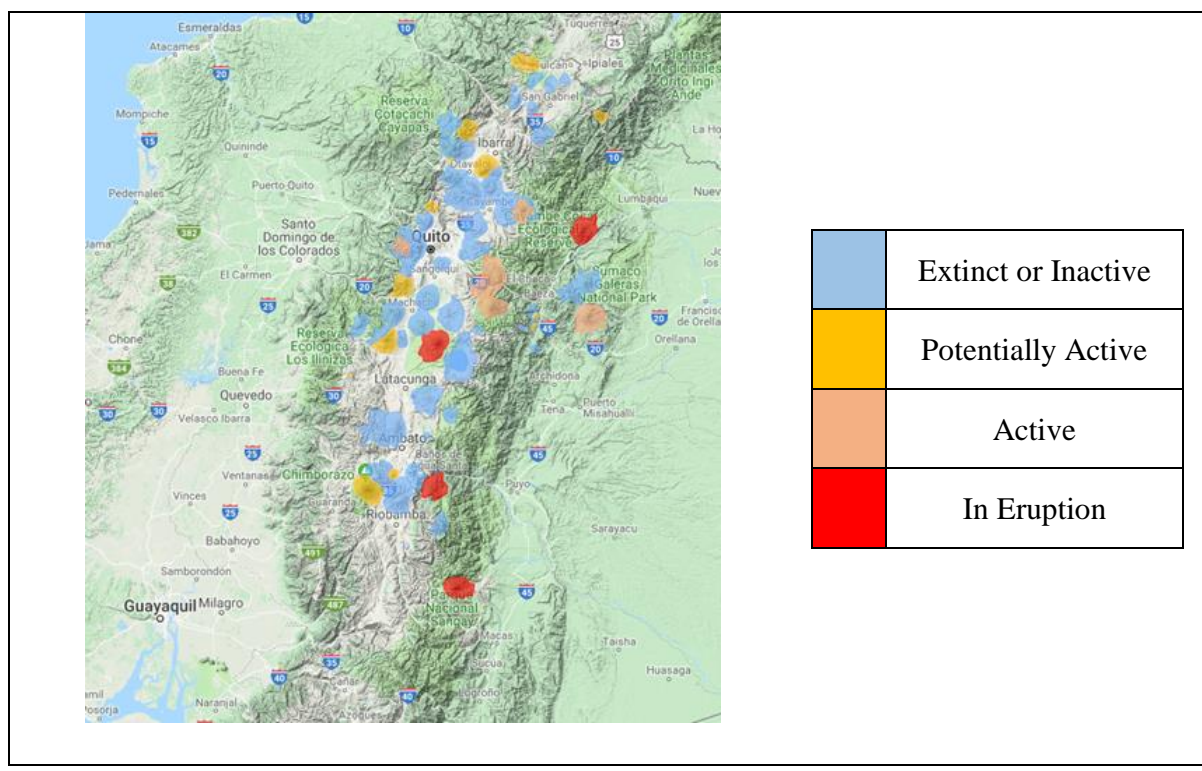

(Bernard \& Andrade, 2011)

Active volcanoes are located nearby cities which imply a risk for the population and infrastructure. Recent eruptions of Guagua Pichincha, Tungurahua (1999), El Reventador (2002), La Cumbre, Fernandina (2005) and Cotopaxi (2015) clearly show the need for monitoring, designing and contingency plans (Aguilera \& Toulkeridis, 2005).

Volcanic explosions not only adversely affect life on the ground but also cause serious problems in aircraft and flight operations by spreading volcanic ash and forming volcanic clouds. With the exponential growth of global population, the air traffic is growing as well; which means more dependence for moving goods around the globe. Luckily, along with all that progress, significant advancements also have been made in the field of volcanology. With the advent of the technology it has been possible to anticipate, assess and mitigate the potential volcanic hazard.

It is important to understand the distinctive concepts of 'prediction' and 'forecasting'. Prediction means a statement about a specific event that will take place within a given timeframe and is inevitable. On the other hand, forecasting denotes a probabilistic statement of a specific event to take place with certain likelihood. There are certain patterns that emerge before the explosion of volcanoes. Therefore, by recognizing and understanding those patterns an eruption and related earthquake forecast could be made.

There is a direct relationship between earthquakes (foreshocks) and the volcanic eruption. It has been noticed that earthquake frequency increases significantly before an eruption on a local level (Minakami, 1960; Klein, 1984; Rubin \& Gillard, 1998; Christopher \& Kilburn, 1998). However, (Jordan, et al., 2011) argued that reliable and accurate earthquake "prediction" is not reliable, except in some special circumstances. For example, a correct prediction was made when the eruption of Mount Helka in Iceland occurred in year 2000. Many 
years before the main eruption, borehole strain meters were deployed within 15 kilometers around the Helka summit, to measure the strain variation. In 1991 an eruption took place, it was observed that magma was emerging from the chamber through a dyke at the depth of 6 kilometers, this observation was done by the aid of systematic strain variation and seismic data. About nine years later, in March 2000 same patterns were noticed again. Given the previous eruption records, an announcement was passed by the Meteorological Office to the Icelandic radio that eruption will start within 20 minutes and it started with the difference of 2 minutes only. Moreover, in perhaps the most famous case of volcanic eruption monitoring of Mount. St. Helens, accurate forecast was done by accurately forecasting the dome protrusion consequences (Swanson, et al., 1983).

The answer for the importance of monitoring lies in the presence of the 500 million people who live at vulnerable locations that can be affected by the eruptions (Newhall, 2000). Volcanism can also lead to the series of hazards that can be very complex for example extreme weathers, earthquakes and landslides that can all trigger together in the form of a chain reaction. The types of the volcanic hazards are mentioned in the Table 1.

Table 1. Hazard type and the related risks intensity, modified after.

\begin{tabular}{cccc}
\hline Hazard & Threat to life & Risk to property & Aerial extent \\
\hline Ash / pumice fall & Low & Depends on roof collapse & Varies but can spread over countries \\
\hline Pyroclastic flow & Very high & Very high & Regional \\
\hline Lahars /Flooding & High to moderate & High & Local/ Regional \\
\hline Lava flows & Low & Very High & Local \\
\hline Acid rain/ Dust & Low to moderate & Moderate & Local/ Regional \\
\hline
\end{tabular}

(Sparks \& Aspinall, 2004)

There are about 10-20 small volcanic events happening every month around the globe that might pose a serious threat to the population and the local economy. However, the catastrophic event capable of disrupting the whole economy of the country can take place approximately every hundred years (Pyle, 1998).

Moreover, it is also necessary to understand the past behavior of a volcano with the aid of geological mapping and the rocks investigation. It is crucial to comprehend the eruption style whether it was explosive or non-explosive or it took place intermittently. Such studies can provide data for the long-term forecasts and can provide enough time to establish various zones based on the risk factor hence mitigating in advance by taking this factor in urban planning and moving existing population to the safer places.

In Ecuador the active volcanoes are monitored by different technologies including seismographs, barometers, GPS and different sensors. The type of instrumentation used in the volcano surveillance depends on the threat for the population living near the volcano [5]. The following study describes the design of a raw prototype of wireless equipment for temperature monitoring of volcanic areas using ZigBee technology. 


\section{METHODOLOGY}

The design of the prototype was divided into two main stages for better understanding of the process:

\subsection{Hardware Design}

The hardware of this prototype consisted of a controller and a mobile device. A PIC (Peripheral Interface Controller) 16F628A was used as the controller, whereas a PIC 16F877A was used as the monitoring mobile device. The controller is comprised of four buttons and one 16x2 LCD (Liquid Crystal Display). Each button controls the mobile's movement direction: forward, backward, left and right. In addition, the temperature measured by the mobile is displayed in the controller. Hence, only digital inputs/outputs were needed for the controller. On the other hand, the mobile device was assembled with a linear temperature sensor LM35, two standard servo-motors and a LED (Light Emitting Diode) to assure its proper functioning. Thus, an analog input was required.

Before wiring each circuit, an electronic scheme was designed in ISIS Proteus 7.

Figure 2 and Figure 3 show the scheme of each device. Thereupon, both circuits where assembled in breadboards.

Figure 2. Mobile temperature monitoring scheme.

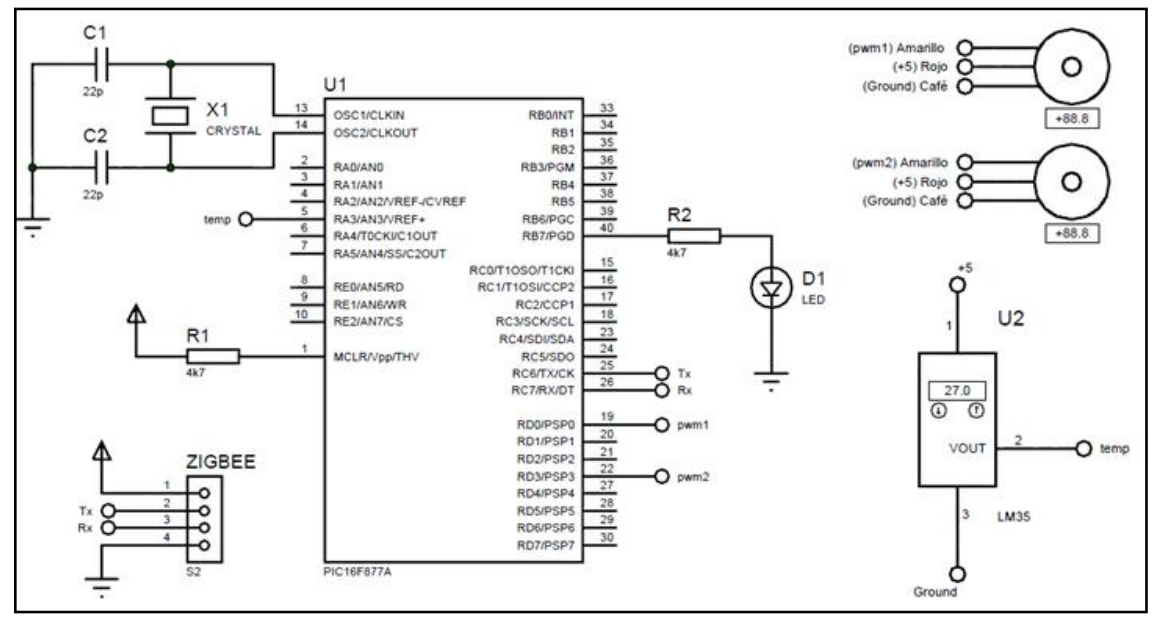

Figure 3. Controller scheme.

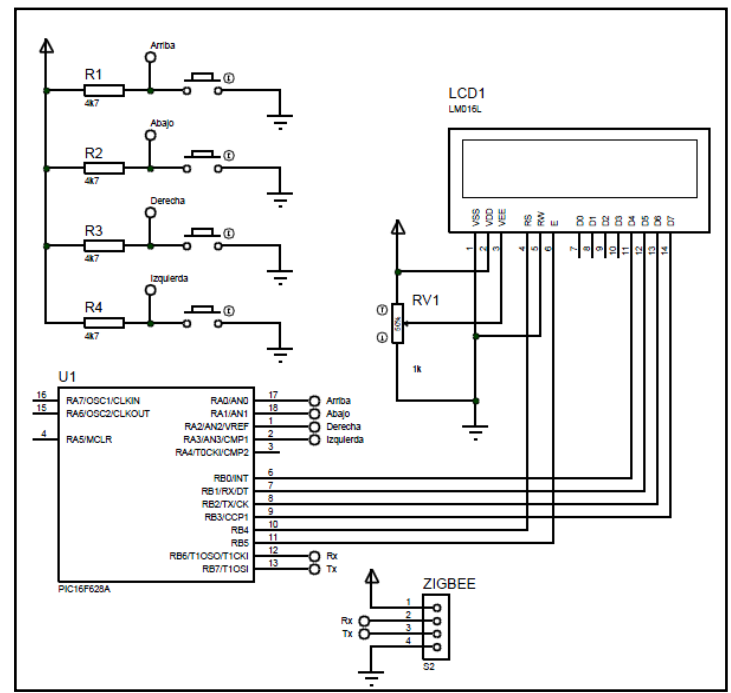




\subsection{Network Setting}

Since PIC microcontrollers were used, the communication protocol chosen was serial due to its facility to work with these devices. The physical interface was composed initially by four cables: reference voltage $(+5 \mathrm{~V})$, ground (GND), Transmitter $(\mathrm{Tx})$ and Receptor $(\mathrm{Rx})$. Firstly, the communication was carried out using conventional copper wires. The controller sent only one data at a time to control the direction of the movement. Each movement instruction was considered as an independent function. Listing. 1, for instance, describes the text to be displayed in the LCD during the serial communication. Number 1 is sent as a character with a baud rate of 9600 [bit $\cdot \mathrm{s}-1]$.

Listing. 1. Forward movement function - Controller.

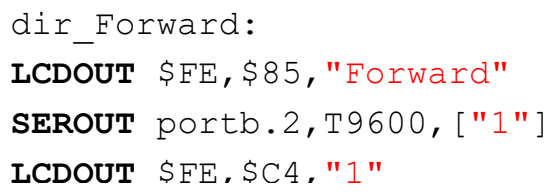

However, the temperature sent from the mobile device was treated as a row of 4 data for a better resolution. Thus, the reception function had to save all four data into a row, convert all of them from ASCCII (American Standard Code for Information Interchange) to decimal numbers and then display the measured temperature.

The baud rate (bits per second) transmission selected for this case was 9600 after several experiments with lower baud rates. Another parameter to limit the baud rate is the characteristic of the wireless device. Once the half-duplex serial communication was synchronized, the wireless devices (ZigBee) were set to replace the copper wires.

Two ZigBee devices were used, both S2 series; one for the controller and one for the mobile device. The difference between them is the capability to work as a router and as a coordinator within a network depending on its configuration (Andersson \& Thoren, 2005). For further purposes, the controller should be able to manage multiple mobile devices (mesh network).

\section{RESULTS}

Figure 4 and Figure 5 show the raw prototype of the controller and the mobile respectively. The communication distance reached up to 75 meters. The displayed temperature was as accurate as the temperature measured by conventional thermometers. However, since the mobile device was assembled with basic electronic components, its linear velocity was approximately $0.25[\mathrm{~m} \cdot \mathrm{s}-1]$.

Figure 4. Controller (Prototype).

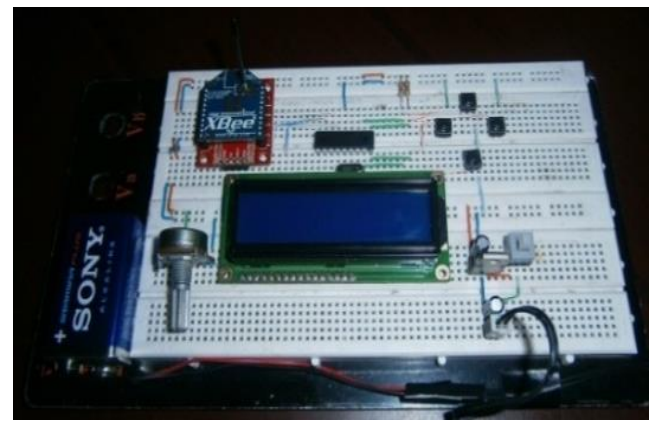


Figure 5. Mobile monitoring device (Prototype).

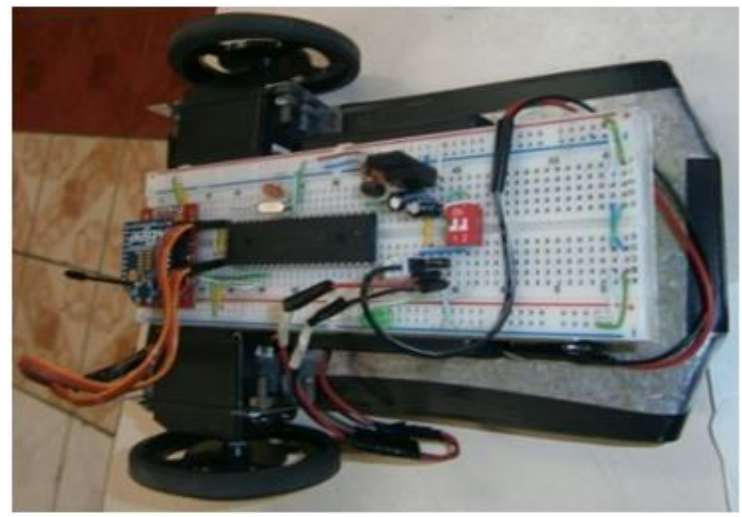

\section{DISCUSSION}

In electronic circuits there are mainly three components: power source, input and output instruments. In order to coordinate those electronic instruments, a programmable controller is usually needed. Once a device has been assembled to work efficiently, the developer could require to communicate with each device or establish a communication between them. Since a sensor is an electronic device which has to be embedded into a circuit, the options to electronically transmit its data are somehow limited. Depending on the network adaptor and the network protocol, the sensor's data could be transmitted via wireless signals or simply by using cables. Regarding wireless options, Bluetooth was highly popular before ZigBee technology appeared. One of the advantageous features of ZigBee is the capability to coordinate multiple nodes and then communicate with other coordinators to finally create a mesh network. Table 2 shows a comparison between some of most popular wireless interfaces. For this specific case of study, ZigBee was chosen due to its reasonable communication range, low cost and low power consumption.

Table 2. Comparison of wireless technology.

\begin{tabular}{llll} 
& \multicolumn{1}{c}{ ZigBee } & \multicolumn{1}{c}{ Wi-Fi } & \multicolumn{1}{c}{ Bluetooth } \\
\cline { 2 - 3 } $\begin{array}{l}\text { Max. speed per } \\
\text { channel }\end{array}$ & $\begin{array}{l}250 \mathrm{kbps}(2.4 \mathrm{GHz}) \\
40 \mathrm{kbps}(915 \mathrm{MHz})\end{array}$ & $11-300 \mathrm{Mbps}$ & Max. 1 Mbps \\
\hline Distance & $10-75 \mathrm{~m}$ & $100 \mathrm{~m}$ (indoor) & $10 \mathrm{~m}$ typical \\
\hline Standard & IEEE 802.15 .4 & IEEE 802.11 & IEEE 802.15.1 \\
\hline Adoption rate & Widely adopted & Extremely high & Extremely high \\
\hline Unique value & $\begin{array}{l}\text { Low cost, low power usage, high } \\
\text { number of nodes }\end{array}$ & $\begin{array}{l}\text { High speed mature } \\
\text { standard }\end{array}$ & $\begin{array}{l}\text { Ease of access, no configuration } \\
\text { requirement, secure connection }\end{array}$ \\
\hline
\end{tabular}

(Sahoo, 2016)

Another remarkable characteristic of the proposed raw prototype is the facility to modify the hardware. Initially, a temperature measurement was effectively performed, but some other parameters can be sensed such as: humidity and vibration. By few changes in the hardware and software, the same device could read more than one variable at a time.

\section{CONCLUSION}

The fact that Ecuador is located in the Ring of Fire makes it extremely vulnerable to the earthquakes and volcanic hazards. Moreover, the presence of four volcanoes that have been in 
eruption for the past few decades and their position just next to the population; contributes to a serious hazard. The human lives cannot be at risk. Hence, there is a need to adopt sophisticated and innovative monitoring techniques to sense the risk before it becomes a catastrophe. Although there have been successful 'forecasts' in the past but with the advancement in the technology, the accuracy can be further improved. Given the mobile nature of ZigBee, it can prove the best up to date technology that can actively monitor the surface temperature in a realtime, even in the areas that are not easily accessible. Furthermore, real-time temperature monitoring can give the clues about the upcoming events, subsequently that information can be delivered to the public that can lead to the safe evacuation of the population before any disaster. Hence ZigBee can prove to be a vital technology to gather data from an inaccessible location.

The raw prototype described above, can result in an important monitoring tool not just in Ecuador but throughout the Ring of Fire. The mobility and versatility of the features that can be added to the equipment can lead to a powerful tool for harsh environments. Moreover, the ZigBee technology utilized, enhances occupational safety by sending the data instead of requiring someone to collect it in the field.

As initially stated, the design described in this study is in its preliminary stages. For this reason, it needs to be updated and has the potential to acquire new features tailored to the monitoring needs. For instance, the servomotors implemented did not reach a required speed. The mobile device itself should cover a wide area. Thus, the mobile's speed should increase by replacing the current servo motors. 


\section{REFERENCES}

AGUILERA, E. \& TOULKERIDIS, T., 2005. El Volcan Cotopaxi, una amenaza que acecha. Quito: s.n.

ANDERSSON, A. \& THOREN, M., 2005. ZigBee: A Suitable Base for Embedded Wireless Development?. Göteborg, Sweden: CHALMERS UNIVERSITY OF TECHNOLOGY.

BERNARD, B. \& ANDRADE, D., 2011. Volcanes Cuaternarios del Ecuador Continental. IGEPN Poster Informativo .

CHRISTOPHER, R. J. \& KILBURN, B. V., 1998. Slow rock fracture as eruption pre-cursor at Soufriere Hills volcano, Montserrat. Geophysical Research Letters, 15(29), p. 36653668 .

Instituto Geofisico Ecuador, 2018. Institutor Geofisico Escuela Politecnica Nacional Ecuador. [Online] Available at: https://www.igepn.edu.ec/red-de-observatorios-vulcanologicosrovig [Accessed 28 January 2018].

JORDAN, T. H. et al., 2011. Operational earthquake forecasting: state of knowledge and guidelines for implementation.. State of Knowledge and Guidelines for Utilization. Annals of Geophysics, 54(4), pp. 316-391.

KLEIN, F. W., 1984. Eruption forecasting at Kilauea volcano. Hawaii,J. Geophys. Res., Volume 89, p. 3059-3073.

MINAKAMI, T., 1960. Fundamental research for predicting volcanic erup-tions - Part I. Earthquake Res. Inst. Univ. Tokyo, Volume 38, p. 497-544.

National Geographic, 2018. Nat Geo Sites. [Online] Available at: https://Www.nationalgeographic.org/encyclopedia/ring-fire/ [Accessed 02 February 2018].

NEWHALL, C. G., 2000. Encyclopaedia of Volcanoes (Chief Editor H. Sigurdsson). Academic Press, p. 1185-1197.

PYLE, D. M., 1998. Forecasting sizes and repose times of future extreme volcanic events.,. Geology, Volume 26, p. 367-370.

RUBIN, A. M. \& GILLARD, D., 1998. Dike-induced earthquakes: Theoretical considerations. J. Geophysics., Volume 103, pp. 10017-10030.

SAHOO, S. K., 2016. Renewable and sustainable energy reviews solar photovoltaic energy progress in India: A review. Renewable and Sustainable Energy Reviews, Volume 59, pp. 927-939.

SPARKS, R. S. J. \& ASPINALL, W. P., 2004. Volcanic Activity: Frontiers and Challenges in Forecasting, Prediction and Risk Assessment Frontiers and Challenges in Geophysics. Geophysical Monograph 150, Volume 19, p. 360.

SWANSON, D. et al., 1983. Predicting eruptions at Mount St. Helens, June 1980 through December 1982.. Science, Volume 221, p. 1369-1376. 